\title{
(2) OPEN ACCESS \\ Distributing leadership for scaling up evidence-based innovation in LMICs: a case for leadership development in India
}

\author{
Graeme Currie (10, ${ }^{1}$ Kamal Gulati 이, ${ }^{2}$ Dimitrios Spyridonidis, ${ }^{1}$ Sridhar Vaitheswaran ${ }^{3}$
}

${ }^{1}$ Warwick Business School, University of Warwick, Coventry, UK

${ }^{2}$ Clinical Epidemiology Unit, All India Institute of Medical Sciences New Delhi, New Delhi, India

${ }^{3}$ Schizophrenia Research Foundation, Chennai, Tamil Nadu, India

\section{Correspondence to} Dr Graeme Currie, Warwick Business School, University of Warwick, Coventry CV4 7AL, UK; graeme.currie@wbs.ac.uk

Received 29 February 2020 Revised 9 July 2020 Accepted 3 March 2021
Check for updates

(c) Author(s) (or their employer(s)) 2021. Re-use permitted under CC BY-NC. No commercial re-use. See rights and permissions. Published by BMJ.

To cite: Currie G, Gulati K, Spyridonidis D, et al. BMJ Leader Published Online First: [please include Day Month Year]. doi:10.1136/ leader-2020-000230

\section{INTRODUCTION}

Distribution of leadership across managers and clinicians, often located in different organisations, is crucial to drive and scale up innovation. ${ }^{12}$ There is a dual drive for leadership development in India, a nation characterised as a low-medium income country (LMIC), that emanates from frontline doctors and from national policy makers, to address the need for innovation in the face of rising costs of healthcare and increasing population demand. Given the size of India, its cultural variation, limited but rising investment in healthcare, geographical variation across states and between urban and rural settings, and its large number of doctors spread across public and private sectors, ${ }^{3}$ any systematic development programme to enable distribution of leadership for innovation presents a significant challenge.

Our aim in this analysis is to make suggestions, however tentative, around the design of a development programme for distribution of leadership towards innovation, which is sensitive to the context of India. We draw from lessons on management literature about the challenges of distributed leadership in healthcare to reflect on what might hold in the Indian context regarding a leadership development programme. We do not assume that lessons are transferable from one national context to another, however drawing on the English experience, which we characterise as only partially successful, alerts us to how we might progress medical leadership development in India.

\section{DISTRIBUTED LEADERSHIP}

In the corporate world, managers are commonly privileged as initiators of innovation, through creating a receptive climate for innovation. ${ }^{4}$ Meanwhile, in healthcare, the notion of the clinical champion innovation remains, commonly drawn from medical ranks. ${ }^{56}$ It seems the notion of the heroic individual leader driving innovation remains. This aligns with professional organisation, within which other clinicians and arguably managers are subordinated to medical power, the latter of which some are 'first among equals' and managerial organisation, where accountability and access to resource concentrates leadership influence. ${ }^{7}$

Yet there are increasing calls, in rhetoric at least, both in the corporate world and healthcare, for a move away from heroic models that privilege individual leaders as driving innovation towards more pluralist leadership. The manager remains important as the source and driver of innovation, particularly in its early phases, creating a receptive climate for innovation, derived from their control over resources and their executive mandate. Doctors are likely to have the greatest leadership legitimacy to drive innovation derived from their clinical and contextual knowledge, and their status. Meanwhile, nurses or other professions allied to medicine also enact leadership to engage their front-line colleagues in innovation and to adapt the innovation to local conditions. Managers may then provide resources to sustain the innovation, and support the business case for scaling up innovation where it relies on external funding, but in general cede leadership to front-line doctors and nurses for innovation over time. ${ }^{2}$

How might leadership development programmes ensure this? Based on the above, one would expect an approach whereby different managers and professionals driving innovation are brought together to focus on developing their collective capacity for innovation. When considering pedagogy that underpins leadership development for innovation, one might expect a problem-centred approach that fits with the training and socialisation of clinicians, so that leadership development is embedded in their practice. ${ }^{8}{ }^{9}$ However, India might learn from the case of England that illustrates a gap between what might represent best practice regarding participation and pedagogy for leadership development orientated towards innovation and what is enacted on the ground.

On the one hand, the National Health Service (NHS) Leadership Academy, the agency responsible for commissioning national programmes at different levels from front-line leadership to executive leadership, has its key objective addressing the 'need to develop the right behaviours to build alliances with a wide range of professionals and across organisational boundaries ... and healthcare leaders at all levels being able to work with leaders in other parts of the public and private system'. And of further significance, the NHS Leadership Academy advocates for healthcare leaders to, 'rely less on an old style command and control approaches that inhibit innovation' (leadershipacademy.nhs.uk). Following this, the NHS Leadership Academy works in close partnership with academic and practice consortia, and regional leadership agencies, to deliver development programmes to realise their key objectives. It also acknowledges the increasing importance of wider determinants of health and emphasises the 
link between health and social care, with professionals from the latter domain of public services participating in the Academy's leadership programmes. Finally, its sheer size and budget (commissioning over $£ 100$ million worth of leadership development in its first year) meant it drove leadership development on an industrial scale with the prospect of widescale systems-level change. $^{10}$

On the other hand, the design of commissioned leadership development programmes is one reliant on acquisition of competences by individual participants, which represents a limited understanding about what leadership is, as it ignores the processual and practice aspect of leadership, in a context where problems are complex ('wicked') rather than 'tame'. ${ }^{11} 12$ Doctors appear poorly represented in the NHS Leadership Academy's programmes, preferring to participate in programmes offered by their professional colleges and associate membership type of organisations such as the Faculty of Medical Leadership and Management (with more than 2000 members and 800 trainees) (https://www.fmlm.ac.uk/cpd) or pursue MBA education in business schools. ${ }^{13}$ Any distribution of leadership for innovation at the local level is rendered even more difficult because the programmes are delivered for different levels of professional and managerial organisation. ${ }^{10}$ This counters a need for leadership to be distributed vertically as well as horizontally in pursuit of innovation. ${ }^{2}$ The underlying assumption of the NHS Leadership Academy's approach to leadership development is that leadership is a quality that is easily transferable from one situation or to another, ignoring the need for leadership development programmes to offer a more contextualised understanding of leadership dynamics. ${ }^{14}$ Even if the formal leadership development programme supports distribution of leadership for innovation, we cannot assume behaviours can be easily enacted at the front line of professional practice, where hierarchies and managerial performance pressures remain pervasive. ${ }^{15}$ It seems India has much to learn from the weaknesses of England's approach to leadership development in the NHS, as well as its strengths, but before translating these to inform our prescriptions, we must consider the Indian context.

\section{THE LEADERSHIP CHALLENGE IN INDIA}

We have already established that leadership development programmes need to account for context if they are to prove effective. ${ }^{14}$ There are a number of features of context in India that add to the difficulty that we reviewed from the English experience of instituting an effective development programme for distributing leadership for innovation in a professionalised organisation that encompasses professional hierarchy and concentrated managerial accountability. ${ }^{15}$

We highlight the sheer scale and diversity of the nation with respect to its healthcare provision, with limited resources. The public healthcare system in India is under enormous pressure in meeting demand from an increasing population (currently around 1.35 billion), facing major challenges including escalating costs, shortage of trained healthcare professionals and having to treat patients with advanced conditions linked to the burden of chronic non-communicable diseases. The government's expenditure on the health sector has grown to $1.4 \%$ in 2018 from 1.2\% in 2014; however it is still lower compared with that of several other developing countries. Expenditure supports a three-tier apex public health system, which at the base includes a vast network of about 30045 primary health centres each serving about 30000 individuals; in the middle, there are 5685 community health centres serving about 100000 followed by district-level hospitals; and at the apex, tertiary-level centres typically in medical schools like the All India Institute of Medical Sciences, New Delhi. Further there is significant variation in provision geographically, with wealthier union territory such as Delhi and more progressive states such as Kerala, enjoying relatively better provision than rural states such as Bihar. A significant proportion of the population is located in outlying rural areas away from centres of clinical excellence, and this necessitates that leadership is distributed further to community leaders if evidence-based innovation is to scale up. There are over 1.2 million allopathic doctors (allied to Western medicine rather than traditional medicine, the latter called Ayurveda, Unani, Siddha and Homeopathy or AYUSH doctors) in India, with $52 \%$ practising in just 5 of India's 29 states. A major bottleneck for scaling up leadership and innovation in the Indian health system is the low level of qualifications generally in the medical workforce. Many individuals claiming to be doctors in their occupation did not have the prerequisite qualifications. Among allopathic doctors, only $31.4 \%$ are educated to secondary school level and $57.3 \%$ do not have a medical qualification. Whereas $58 \%$ of doctors in urban areas had a medical degree, only $19 \%$ of those had such a qualification in rural areas. Indeed the number of those claiming the status of doctors can be challenged. Meanwhile, qualifications and level of skills of nurses and other professions allied to medicine is much below that of doctors. ${ }^{16}$ This is likely to have consequences for leadership development, particularly any attempt to widen participation beyond the more qualified and senior doctors.

Nevertheless, policy makers' still aim to build leadership capacity for innovation in the face of rising costs of healthcare and increasing population demand. This is reflected in the National Health Policy, 2017 which states: 'buman resource management is critical to health system strengthening and healthcare delivery... Policy recommends development of leadership skills, strengthening human resource governance in public health system, through establishment of robust recruitment, selection, promotion and transfer postings policies' (Ministry of Health and Family Welfare, page-21, point no. 11.9). ${ }^{17}$

Dialogue regarding how leadership development is best pursued in India is dominated by a culturalist perspective, which argues there are certain culture-specific expectations, shared by leaders and followers alike, that arise from wider socialisation patterns within society. There is a preference for hierarchy, with relative status determining the relationship between leader and follower, with the former a benevolent source of influence for the latter, provided the follower is seen to work hard and be productive. The relationship is one that is highly personalised. ${ }^{18-20}$ The dominance of doctors in the clinical hierarchy within India is more pronounced than in England ${ }^{21}$ and will likely render distribution of leadership more challenging. Yet the leader-follower relationship that is traditional in India is one subject to change in the face of liberalisation of the Indian economy and imperatives of globalisation, and this is likely to seep into development of leadership among the healthcare workforce, with a need to synthesise Anglo-American and Indian cultures and practices in healthcare delivery, with associated consequences for leadership development. 2223

National Indian institutions such as the Public Health Foundation of India, New Delhi; the Datta Meghe Institute of Medical Sciences, Wardha; the All India Institute of Medical Sciences, New Delhi; and the Symbiosis College of Nursing, Pune, have moved into this space for leadership development and have delivered leadership interventions to clinicians, although they are orientated towards doctors and follow a competence-based 
approach. Research about competence-based leadership development in India reveals widespread acceptance among doctors that they feel it is necessary and something they willingly engage in should it be offered, and despite low level of educational attainment among doctors, a significant proportion (just under half in one study) desired a postgraduate level qualification in the area, although many (in the same study a third) rendering this exclusive to consultant level. At the same time, pedagogically, doctors expressed a preference for the type of problem-centred approach that would suit leadership development for innovation, using case studies of successes and failures, project/fieldbased learning and team-based learning, rather than traditional classroom-based didactic learning. ${ }^{24-26}$ The competence-based approach can accommodate such approaches to learning; nevertheless, as highlighted before, competence-based approaches do not easily lend themselves towards developing the distributed leadership necessary to implement and scale up innovation when faced with wicked issues. ${ }^{11} 12{ }^{16}$ Meanwhile the size of India's clinical workforce and its low level of educational attainment outside doctors, means the system-wide intervention evident in England is likely impossible. Yet, pressures dictate the need for systematic leadership development to address wicked issues, so what might we prescribe to move India forward in this regard?

\section{THE WAY FORWARD FOR INDIA}

So, there appears a strong need for leadership development that encourages distributed leadership orientated towards innovation in India, but a challenging context in which to do this. The economic, workforce and cultural contexts of India mean that there prevails leadership development that encourages enactment of a hierarchical model of leadership, and which remains the preserve of the most senior doctors. Further, similarly to England, the limited amount of leadership development currently prevalent in India delivers a competence-based model, with all its inherent weaknesses. Those designing leadership development programmes in India should view leadership as a process that requires distribution across clinicians and organisations for innovation to be realised. We draw on a systematic leadership intervention in a relatively well-resourced health system, England, to offer lessons for India. The scale of India and the size of its healthcare challenges is, however, worthy of specific attention, following which we offer the following prescriptions for India:

1. India should move towards more relational forms of leadership development that recognise that leadership is a distributed process particularly when faced with complex issues, rather than a set of competencies held by individuals.

2. Nevertheless leadership development needs to be contextualised for India in the face of economic, workforce and cultural challenges.

3. In contrast to England, where leadership development is delivered to the wider clinical and managerial workforce, in India we might only deliver development programmes for distributed leadership to senior doctors educated up to graduate level. Following this, we might encourage and support them to distribute leadership to their medical peers at the local level. Currently educational level of the non-medical (and indeed some of the medical) workforce means leadership development needs are secondary to clinical education for the wider workforce.

4. We recognise healthcare provision does not stand alone, with a particular need for integrated service provision, not just across hospitals and community healthcare, but across social care and other public services domains. As above, however, we suggest a pragmatic approach whereby we focus on leadership in healthcare, with those senior doctors participating in leadership development programmes reaching out to other parts of the system. One aspect of leadership development may be enhancing their capacity to engage others in leadership, particularly in rural areas, within which community leaders may be engaged in innovation.

5. Ensure that a national mandate exists for leadership development for doctors across India. Given its size and variation socio-economically, culturally and between rural and urban populations, then State agencies, medical schools and professional bodies need to be engaged and given autonomy in the development and delivery of programmes at the local lev$\mathrm{el}$, at the same time as some central control exists. As with England, the mandate might be supported by national-level investment to fire up the leadership development system.

6. Finally, in the wake of COVID-19, resource constraints in India may be more severe following the economic downturn. Nevertheless, we stress the need for leadership of innovation is now greater, and barriers to distribution of leadership may dissipate as the innovation imperative becomes even more obvious. We thus encourage Indian policy makers to provide resourcing for leadership development programmes.

Collaborators Professor Swaran Singh, Warwick Medical school, University of Warwick, Coventry; Dr Rangaswamy Thara, Schizophrenia Research Foundation (SCARF), West Anna Nagar Extension, Chennai; India study group: National Institute for Health Research Warwick-India-Canada (WICs) Network.

Contributors GC, KG, DS, SV have contributed to the commentary and to the discussion about its message. GC took the lead in writing, and KG and SV provided a synthesis of the literature about leadership development in India.

Funding This study was funded by the National Institute for Health Research Warwick-India-Canada (WICs) Network.

Competing interests None declared.

Patient consent for publication Not required.

Provenance and peer review Not commissioned; externally peer reviewed.

Open access This is an open access article distributed in accordance with the Creative Commons Attribution Non Commercial (CC BY-NC 4.0) license, which permits others to distribute, remix, adapt, build upon this work non-commercially, and license their derivative works on different terms, provided the original work is properly cited, appropriate credit is given, any changes made indicated, and the use is non-commercial. See: http://creativecommons.org/licenses/by-nc/4.0/.

\section{ORCID iDs}

Graeme Currie http://orcid.org/0000-0002-4825-9711

Kamal Gulati http://orcid.org/0000-0001-7681-0497

\section{REFERENCES}

1 Greenhalgh T, Robert G, Macfarlane F, et al. Diffusion of innovations in service organizations: systematic review and recommendations. Milbank $Q$ 2004:82:581-629.

2 Currie G, Spyridonidis D. Sharing leadership for diffusion of innovation in professionalized settings. Hum Relat 2019;72:1209-33.

3 Chauhan LS. Public health in India: issues and challenges. Indian J Public Health 2011;55:88.

4 Mumford MD, Scott GM, Gaddis B, et al. Leading creative people: orchestrating expertise and relationships. Leadersh Q 2002;13:705-50.

5 Locock L, Dopson S, Chambers D, et al. Understanding the role of opinion leaders in improving clinical effectiveness. Soc Sci Med 2001;53:745-57.

6 Shaw EK, Howard J, West DR, et al. The role of the champion in primary care change efforts: from the state networks of Colorado ambulatory practices and partners (SNOCAP). J Am Board Fam Med 2012;25:676-85.

7 Raelin JR. The clash of cultures: managers and professionals. Cambridge, MA: Harvard Business School Press, 1986.

8 Baird DS, Soldanska M, Anderson B, et al. Current leadership training in dermatology residency programs: a survey. J Am Acad Dermatol 2012;66:622-5. 
9 Awad SS, Hayley B, Fagan SP, Samir SA, et al. The impact of a novel resident leadership training curriculum. Am J Surg 2004;188:481-4.

10 NHS Leadership Academy. Towards a new model of leadership, 2013. Available: https://www.leadershipacademy.nhs.uk/wp-content/uploads/2013/05/Towards-aNew-Model-of-Leadership-2013.pdf

11 Edmonstone J. The challenge of capability in leadership development. Br J Health Care Manag 2011;17:572-8.

12 Raelin JA. Leadership-as-Practice: theory and application. London: Routledge, 2016.

13 McGivern G, Currie G, Ferlie E, et al. Hybrid manager-professionals' identity work: The maintenance and hybridization of professionalism in managerial contexts. Public Adm 2015;93:412-32.

14 Liden RC, Antonakis J. Considering context in psychological leadership research. Hum Relat 2009;62:1587-605.

15 Currie G, Lockett A. Distributing leadership in health and social care: collective concertive and conjoint? Int Manag Rev 2011;13:286-300.

16 World Health Organization. The health workforce in India. human resource and health observer series, 2016

17 Ministry of Health and Family Welfare. Backdrop to national health policy 2017: situation analyses, 2017. Available: https://mohfw.gov.in/sites/default/files/ 9147562941489753121.pdf [Accessed 29 May 2020].
18 Garg P, Parikh L. Managers and corporate cultures: the case of Indian organizations. Manag Int Rev 1986;26:50-62.

19 Palrecha R, Spangler WD, Yammarino FJ. A comparative study of three leadership approaches in India. Leadersh Q 2012;23:146-62.

20 Sinha JBP. The cultural context of leadership and power. New Delhi: Sage, 1995.

21 Sheikh K. Analyzing power in health systems: the case of medical dominance in India. BMC Proc 2012;6.

22 Chachra V, Sanni S, Bansal R. Emerging leadership development trends in India. Cambridge, MA: Harvard Business Publishing, 2011.

23 Reddy CM, Srinivasan V. Dialogue on leadership development. In: Indian Institute of management Bangalore management review. , 2015: 27, 44-55.

24 Gulati K, Singh AR, Kumar S, et al. Impact of a leadership development programme for physicians in India. Leadersh Health Serv 2019;33:73-84.

25 Gulati K, Sarkar C, Verma V, et al. Assessment of medical leadership competencies and development needs: first comprehensive study from India. Int J Healthc Manag 2019;25:1-12.

26 Gulati K, Madhukar V, Verma V, et al. Medical leadership competencies: a comparative study of physicians in public and private sector hospitals in India. Int I Health Plann Manage 2019;34:e947-63. 